\title{
OUR EXPERIENCE WITH THE USE OF INTRAOPERATIVE ULTRASOUND IN SURGERY FOR COLORECTAL LIVER METASTASES
}

\author{
Vazharov I. \\ Multiprofile Hospital for Active Treatment - Varna Military Medical Academy \\ Reviewed by: prof. R. Madjov
}

\begin{abstract}
PURPOSES: To share our experience of routine application of IOUS in resection of liver metastases of colorectal carcinoma. MATERIALS AND METHODS: This is a prospective study of 50 patients with colorectal liver metastases. The involvement of the liver is examined preoperatively by transcutaneous ultrasound examination and contrast-enhanced computer tomography and inspection, palpation and intraoperative ultrasound during the operative intervention. The number and localization of the liver lesions are compared with the preoperative results and the focal changes are confirmed histologically. RESULTS: IOUS detected additional lesions in 23 patients $/ 46 \%$ / and lead to a change of the operative plan in 19 patients $\mathbf{3 8 \%} \%$. The malignancy of the lesions is confirmed by histological examination. In 1 patient $/ 2 \% /$ the histological diagnosis was hemangioma in spite of the fact that the preoperative graphic examinations and IOUS showed malignant characteristics. 5 patients $/ 10 \%$ / were considered as inoperable due to IOUS because of the multiple bilobar lesions, and in 1 patient $/ 2 \%$ / the lesion described with the preoperative CECT was not found. CONCLUSIONS: The routine use of IOUS in patients with malignant diseases improves the detection of liver lesions and helps the surgeon to choose the appropriate strategy for liver resection.
\end{abstract}

Key words: colorectal liver metastases, transcutaneous ultrasound, intraoperative ultrasound, computer tomography

\section{INTRODUCTION}

Colorectal cancer is the third most commonly diagnosed cancer in males and the second in females, with over 1.2 million new cancer cases and 608,700 deaths estimated to have occurred in 2008. Approximately $50-60 \%$ of the patients develop colorectal liver metastases /CRLM/. The average survival rate of the patients with CRLM without treatment is 6-9 months depending on the spread of the disease at the time of diagnosing (3). The main cause of death of the patients with CRLM are the distant metastases (4). The liver resection is the main choice of treatment in patients with CRLM with 5 years survival rate over $50 \%$ (5). The alternative treatment is the local treatment cryoablation, radiofrequency ablation, which are used in non resectable tumors and contraindications for an operative treatment, but their efficacy is still assessed (6). Nevertheless the liver metastases are resected the 5 year survival rate is still $20-40 \%$ (7). Here in this study we share our ex-

Address for correspondence:

Iv. Vazharov, Multiprofile Hospital for Active Treatment - Varna

Military Medical Academy

e-mail: vajarov@dir.bg perience with the use of IOUS during the operation to remove the colorectal liver metastases.

\section{PATIENTS AND METHODS}

The study includes totally 50 consecutive patients from February 2007 to January 2011. They are evaluated preoperatively with anamnesis, physical examination, serum laboratory tests, transcutaneous ultrasound examination and computer tomography of the liver and considered suitable for operation for CRLM. The study consisted of 28 men and 22 women, 22 men and 18 women with cancer of the colon and carcinoma recti had 4 men and 6 women. The average age of the men with cancer of the colon is 65 years /range 40-78/ and the women respectively 61 years /range 38-79/. The average age of the men with carcinoma recti was 63,6 years /range 47-81/, and the women respectively $65 /$ range 51-79/. The examination was approved by the ethical committee of MHAT Varna MMA and all of the patients signed informed consent for the examinations. All of the procedures correspond to the ethical standards of the World medical association /Declaration of Helsinki/. 


\section{Transcutaneous ultrasound of liver}

The transcutaneous ultrasound of liver is performed with apparatus Aloka 4000+/Aloka Co. Ltd. Tokyo, Japan/with 3.5 MHz electrone convex transducer and Doppler / Colour Doppler: 5,0/6,0 MHx maximum one week before the operation. The examinations were performed by a specialist of gastroenterology with professional qualification of abdominal, Doppler and interventional ultrasound examination as a routine clinical method.

\section{Computer tomography}

Computer tomography of the upper abdomen was performed in all patients in order to estimate the focal changes in the liver. CT scanning was performed in other medical institutions. The period between the time of examination and the operation was maximum 4 weeks. All CT examinations were performed with i.v. contrast agents. CT examination is interpreted by a specialist roentgenologist as a routine clinical method.

\section{Intraoperative ultrasound}

UST-MC11-8731 Aloka Ultrasound electronic convex intraoperative transducer /fig.1/, which is ultrasound apparatus Aloka 40000+ /Aloka Co. Ltd. Tokyo, Japan/. Zone of scanning 650 , radius $20 \mathrm{~mm}$. Eligible working frequencies of the transducer: B - regimen: 5,0 / 6,0 / 7,5 / 10,0 MHz. Doppler /Color Doppler: 5,0 / 6,0 MHz. The latter is sterilized after each examination with formaldehyde.

All examinations are performed by specialist gastroenterologist with professional qualification of abdominal, Doppler and interventional ultrasound. Both lobes are examined, and particular attention was paid to the lobe, which must be preserved /and it's supposed that it is free of metastases from the results of the preoperative ultrasound and computer tomography/.

\section{Resection of the liver}

The resection of the liver was performed by a surgeon trained in liver surgery. In each patient the liver was inspected and palpated by the surgeon. The rest of the abdomen was examined for extra hepatic metastases. The surgical procedure in all patients was mono- or bisegmentectomia, hemihepatectomia or trisectionectomia.

\section{RESULTS}

From all the 50 patients IOUS found additional lesions in 23 of them $/ 46 \%$ / and in $4 / 8 \% /$ the liver was assessed by the preoperative examinations as not engaged by metastases. The malignancy of the lesions is confirmed with histological examination. In 1 patient $/ 2 \% /$ the histological diagnosis was hemangioma, although the preoperative examinations and IOUS had the characteristics of a malignant lesion. We must note that the patient had a serious steatosis on the basis of the preoperative chemotherapy. A change of the operative plan occurred in 19 patients $/ 38 \% / .5$ patients $/ 10 \% /$ due to IOUS were considered inop- erable because of the multiple bilobar lesions, and in 1 patient $/ 2 \% /$ the lesion described by the preoperative contrast-enhanced computer tomography was not found. In 14 $128 \% /$ IOUS helped to find the relations of the tumor with the blood vessels of the liver.

\section{DISCUSSION}

Our study showed that IOUS finds significant application in liver surgery for primary or secondary neoplasms of the liver.

The preoperative graphic modalities have their limitations when estimating liver lesions. The ultrasound examination is widely used and cheap method. Although it is not as sensitive as CT MRI for detection of focal solid lesions (8). The reported rate of sensitivity of the ultrasound examination for detection of hepatic metastases varied from $40 \%$ to $60 \%$ (9). It's particularly difficult in: Macronodular cirrhosis with multiple regenerative nodules under $2 \mathrm{~cm}$, expressed fibrosis, atrophy of the liver with inter positioning of the intestines; expressed steatosis (10). The presence of diffuse hepatic disease reduces the sensitivity of the ultrasound examination either.

The spiral contrast-enhanced CT is the basic instrumental examination for preoperative staging of the patients with known or suspicious colorectal carcinoma (11). The sensitivity of CT for CLM is reported $73-85 \%(2,12)$.

Up to $60 \%$ of the metastases are missed by the ultrasound examination and computer tomography, especially those smaller than $10 \mathrm{~mm}$, and thus influence the efficacy of the surgical and non operative treatment. In these cases the MRI is generally accepted as the fundamental equipment for additional graphic estimation of the liver. MRI contrast agents can be safely used in case of renal insufficiency. The main disadvantages of MRI are the high price, the long duration of the procedure and the necessity to hold one's breath for a long period of time.

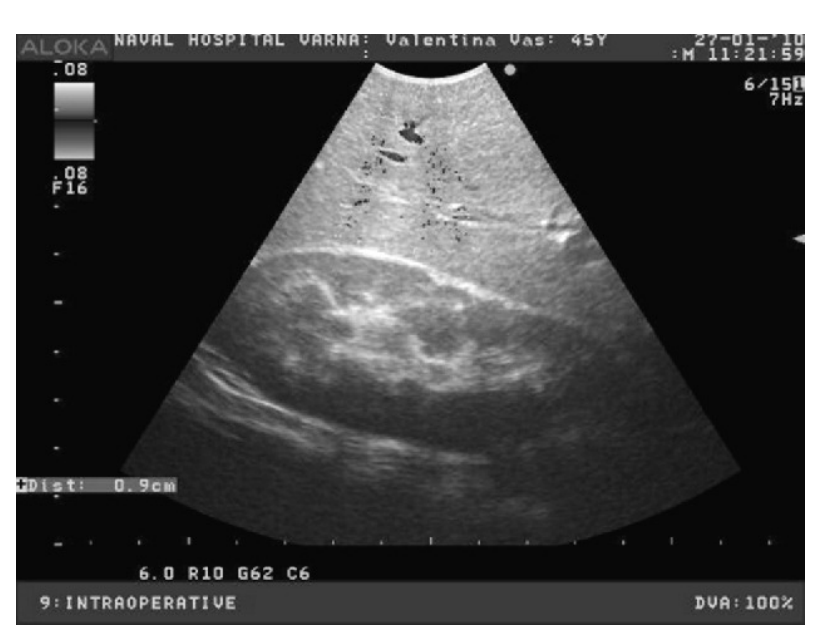

Picture 1. Isoechogenic metastasis measuring $9 \mathrm{~mm}$.

The present graphic technology can detect all the metastases over $2 \mathrm{~cm}$ and more of those measuring from 1 
to $2 \mathrm{~cm}$. Nowadays even with the most contemporary graphic technologies only half of the nodules smaller than 1 $\mathrm{cm}$ are detected in patients who undergo liver resection with histological verification (15).

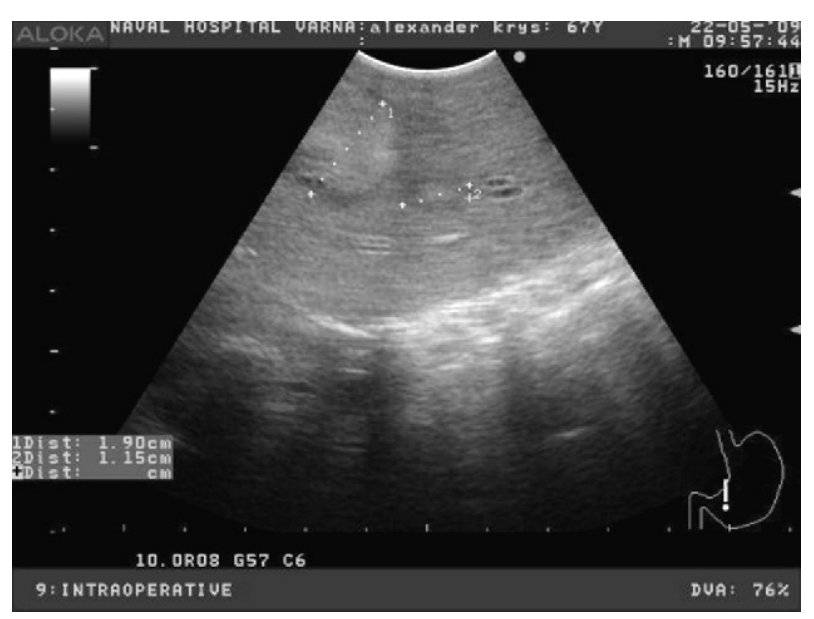

Picture 2. Two hyperechogenic metastases with hypoechogenic zone measuring 19 and $11 \mathrm{~mm}$.

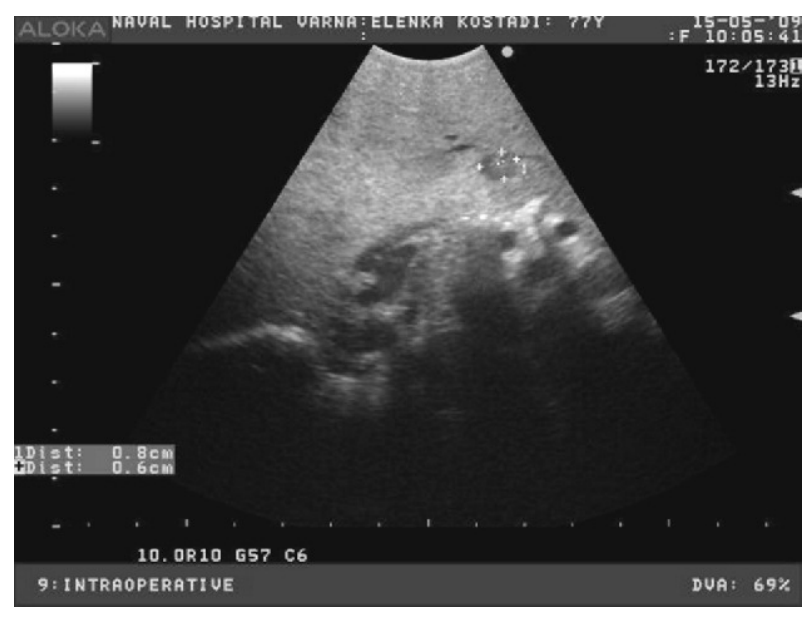

Picture 3. Hypoechogenic metastasis measuring $9 \mathrm{~mm}$.

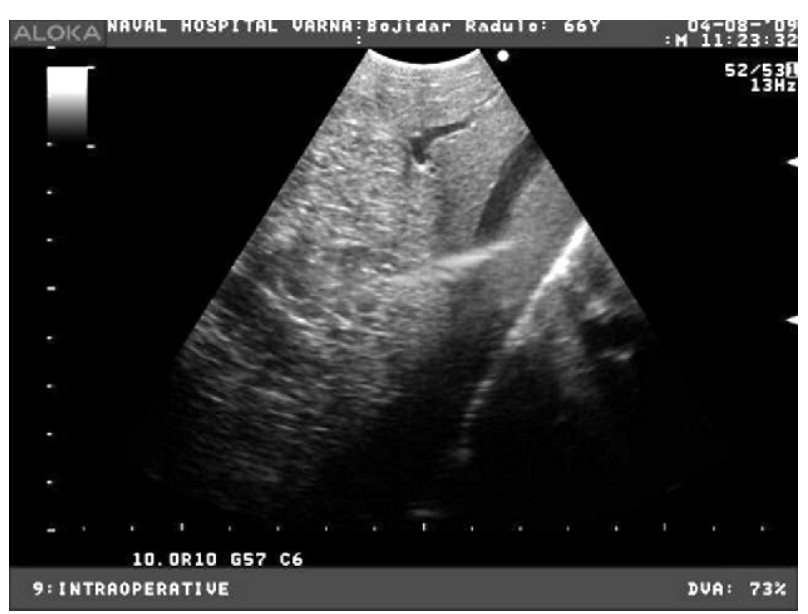

Picture 4. Metastasis with mixed echogenicity measuring $100 \mathrm{~mm}$.
IOUS changed considerably the hepatobiliary surgery because it's the only modality giving information of the inside of the liver in real time during the operation. The basic advantages of IOUS are detection of additional tumors or other focal lesions in $27 \%$ (16) - $55 \%$ (17) and estimation of their relation with the main vessels (18).

The disadvantages of IOUS include the low specificity, which also depends on the experience of the practitioner, the prolonged time of the surgical procedure and high cost of the operation (19). The sensitivity of IOUS is up to $99 \%$ according to different studies (20) and specificity $95 \%$ $100 \%$ regarding the number, spread and localization of the liver lesions and their connection with the large vessels and biliary structures (21). IOUS balances between radical operation and preserving the hepatic parenchyma. The precise identification of the anatomy of the hepatic veins permits hepatectomias impossible without IOUS, and thus expanding the indications of surgical resection (22). On the other hand the precise staging of the hepatic tumors prevents unnecessary surgical procedures.

Under IOUS control invasive procedures can be performed - puncture and sclerosing of small metastases (24). The benign and the malignant tumors may shift the blood vessels, and the latter must be traced and marked on the capsule of the liver. This shifting is not a contraindication for tumor resection, but the vascular invasion is a contraindication for resection (25). Thus IOUS finds out important information which was not detected at the preoperative graphic examination and changes the surgical approach in $19 \%-65 \%$ of the cases (26).

In conclusion IOUS helps considerably in surgery of colorectal liver metastases. Besides finding new lesions and changing the surgical strategy in some patients, it helps to preserve the hepatic parenchyma while the operation is radical, by identification of the relations between the tumor and the intrahepatic vascular net. Many authors state that hepatic resection becomes a procedure controlled by IOUS and like every procedure directed by graphic modality it has a high therapeutic efficiency combined with minimum invasiveness.

Taking this into consideration, the resection directed by IOUS becomes the method of choice in the operative treatment of colorectal liver metastases.

\section{REFERENCES}

1. Jemal A, Bray B, Center M et al. Global cancer statistics 2008. CA Cancer J Clin. 2011; 61(2): 69-90

2. Shah AJ, Callaway M, Thomas MG et al. Contrast-enhanced intraoperative ultrasound improves detection of liver metastases during surgery for primary colorectal cancer. HPB (Oxford). 2010; 12(3): 181-7

3. Vadeyar HJ. Current therapeutic options for colorectal liver metastases. Indian J Gastroenterol. 2007; 26(1): 26-9 
4. Alberts S, Wagman L. Chemotherapy for Colorectal Cancer Liver Metastases. The Oncologist 2008; 13(10): 1063-1073

5. Small R, Lubezky N, Ben-Haim M Current controversies in the surgical management of colorectal cancer metastases to the liver. Isr Med Assoc J. 2007; 9(10): 742-7

6. Vadeyar HJ. Current therapeutic options for colorectal liver metastases. Indian J Gastroenterol. 2007;26(1):26-9

7. Fujita S, Akasu T, Moriya Y. Resection of synchronous liver metastases from colorectal cancer. $J p n$ J Clin Oncol. 2000; 30(1): 7-11

8. Glover C, Douse P, Kane P et al. Accuracy of investigations for asymptomatic colorectal liver metastases. Dis Colon Rectum 2002;45:476-484

9. Paulson EK. Evaluation of the liver for metastatic disease. Semin Liver Dis 2001;21:225-236

10. Контрастно - усилена ехография със SonoVue. Митова Р., Григоров Н., Генов Й. и др.

Диагостичин и терапевтичен ултразвук. 2007; 1 : 3-15

11. Kim KW, Kim AY, Kim TK et al. Small $(2 \mathrm{~cm})$ Hepatic Lesions in Colorectal Cancer Patients: Detection and Characterization on Mangafodipir Trisodium-Enhanced MRI; AJR 2004; 182:1233-1240

12. Bhattacharjya $\mathrm{S}, \mathrm{Bhattacharjya} \mathrm{T,Baber} \mathrm{S}$ et al. Prospective study of contrast-enhanced computed tomography, computed tomography during arterioportography, and magnetic resonance imaging for staging colorectal liver metastases for liver resection. Br J Surg. 2004; 91(10): 1361-1369.

13. Schima W, Kulinna C, Langenberger $\mathrm{H}$ et al. Liver metastases of colorectal cancer: US, CT or MR? Cancer Imaging. 2005; 5: 149-56

14. Kamel IR, Bluemke DA. MR imaging of liver tumors. Radiol Clin North Am 2003;41:51-65

15. Robins on P; Imaging liver metastases: current limitations and future prospects; Br J Radiol. 2000; 73(867):234-41

16. Scaife CL., Ng CS., Ellis LM. Et al. Accuracy of preoperative imaging of hepatic tumors with heli- cal computed tomography. Annals of Surgical Oncology. 2006; 13(4): 542-6.

17. Zacherl J, Scheuba C, Inhof M, Zacherl M, Langle F, Pokieser P, et al. Current value of intraoperative sonography during surgery for hepatic neoplasms. World J Surg 2002; 26 (2): 550-4.

18. Dushyant V. Sahani, MD, Sanjeeva P. et al. Intraoperative US in Patients Undergoing Surgery for Liver Neoplasms: Comparison with MR Imaging. $R a$ diology 2004; 232(2): 810-814

19. Sahani DV, Kalva SP, Tanabe KK er al. Intraoperative US in Patients Undergoing Surgery for Liver Neoplasms: Comparison with MR Imaging. $R a$ diology 2004; 232:810-814.

20. Silberhumer GR, Steininger R, Laengle F. et al. Intraoperative ultrasonography in patients who undergo liver resection or transplantation for hepatocellular carcinoma. Surg Technol Int. 2004;12:145-51.

21. Fioole B, de Haas RJ, Wicherts DA et al. Additional value of contrast enhanced intraoperative ultrasound for colorectal liver metastases. Eur J Radiol. 2008; 67(1): 169-76.

22. Torzilli G, Leoni P, Gendarini A. Ultrasound-guided liver resections for hepatocellular carcinoma. Hepatogastroenterology. 2002; 49(43): 21-7

23. Ozsunar Y, Skjoldbye B, Court-Payen M et al. Impact of intraoperative ultrasonography on surgical treatment of liver tumours. Acta Radiol. 2000; 41(1):97-101.

24. Shkrob OS, Dadvani SA, Kuzin NM et al. Intraoperative ultrasonography in surgery on organs of abdominal cavity and retroperitoneal space.

Khirurgiia (Mosk) 2000; (2):28-32

25. Ozsunar Y, Skjoldbye B, Court-Payen M et al. Impact of intraoperative ultrasonography on surgical treatment of liver tumours. Acta Radiol. 2000; 41(1):97-101

26. Sietses C, Meijerink MR, Meijer S et al. The impact of intraoperative ultrasonography on the surgical treatment of patients with colorectal liver metastases. Surg Endosc. 2010; 24(8): 1917-22 